\title{
PERIGO DE CONTAMINAÇÃO DA ÁGUA SUBTERRÂNEA NA REGIÃO DE INDAIATUBA A CAPIVARI, ESTADO DE SÃO PAULO, BRASIL
}

Mara Akie IRITANI

Denise ROSSINI-PENTEADO

Sibele EZAKI

Geraldo Hideo ODA

\begin{abstract}
RESUMO
O mapeamento do perigo de contaminação dos aquíferos auxilia o planejamento do uso e ocupação do solo, indicando prioridades para o controle das atividades antrópicas e para a proteção das captações de água subterrânea. Considerando o perigo como resultado da interação entre a vulnerabilidade natural dos aquíferos e a carga potencial contaminante imposta por atividades antrópicas, neste trabalho o sistema de classificação do perigo de contaminação da água subterrânea foi adaptado para permitir o mapeamento com base em técnicas de análise espacial em SIG (Sistema de Informação Geográfica). O mapeamento do perigo de contaminação da água subterrânea foi realizado em uma área que abrange seis municípios localizados no leste do estado de São Paulo, Brasil, caracterizada por um expressivo desenvolvimento econômico e acentuado processo de expansão urbana. O mapa de perigo de contaminação associado às fontes pontuais de contaminação indicou que as áreas mais críticas estão nos distritos industriais de Indaiatuba e de Salto e em áreas dispersas ao longo do rio Capivari e das rodovias. Na área urbana, o perigo de contaminação associado ao sistema de saneamento está concentrado nas porções com urbanização mais antiga e com maior densidade de ocupação. $\mathrm{Na}$ área rural, os setores com perigo alto a moderado de contaminação ocorrem, principalmente, na porção oeste da área estudada, onde predomina a monocultura canavieira. Em relação às fontes difusas, as áreas com moderado a muito baixo perigo de contaminação apresentam maior extensão, resultante da baixa vulnerabilidade dos aquíferos na região. Considerando o aspecto dinâmico do uso e ocupação do solo, o mapa de perigo de contaminação da água subterrânea deve ser atualizado periodicamente para melhor subsidiar as ações de planejamento e, nesse sentido, as ferramentas de geoprocessamento facilitam a tarefa.
\end{abstract}

Palavras-chave: Perigo de contaminação da água subterrânea; Proteção da água subterrânea; Sistema Aquífero Tubarão; SIG; Região de Indaiatuba a Capivari; UGRHI 5.

ABSTRACT

GROUNDWATER CONTAMINATION HAZARD IN THE INDAIATUBA TO CAPIVARI REGION, STATE OF SÃO PAULO, BRAZIL. The mapping of groundwater contamination hazard is a helpful tool for planning land use, identifying priorities for controlling human activities and for protecting groundwater sources. Considering hazard as a result of the interaction between the aquifer natural vulnerability and the potential contaminant load imposed by human activities, in this study, the classification system for groundwater contamination hazard was adapted to allow mapping based on spatial analysis techniques in GIS (Geographic Information System). The groundwater contamination hazard was mapped in an area comprised by six cities, which are located in the eastern part of São Paulo State, Brazil, and experienced significant economic development and accelerated urban expansion. The 
groundwater contamination hazard map associated with point sources of contamination indicated that critical areas are located in the industrial districts of Indaiatuba and Salto and are scattered along the Capivari River and highways. In urban areas, the risk of contamination associated to leakage of sewage systems is concentrated in older parts of the city with high density of occupation. In rural areas, the risk of contamination is high or moderate mainly in the western portion of the study area, which is dominated by sugarcane monoculture. With regard to diffuse contamination sources, there is a predominance of areas with moderate to very low contamination hazard resulting from the low aquifer vulnerability in the region. Considering the dynamics of land use, the groundwater contamination hazard map must be regularly updated to better support groundwater management and land use planning and geoprocessing tools can facilitate this task.

Keywords: Groundwater contamination hazard; Groundwater protection; Tubarão Aquifer System; GIS; Indaiatuba to Capivari region, UGRHI 5.

\section{INTRODUÇÃO}

O perigo de contaminação da água subterrânea corresponde à probabilidade de um aquífero sofrer impactos negativos causados pela atividade antrópica, de tal maneira que a água deixe de atender aos padrões estabelecidos para o consumo humano (FOSTER et al. 2002). O perigo depende das características do meio a ser afetado (aquífero) e das fontes potenciais que possam liberar compostos contaminantes ao ambiente (atividades antrópicas). Assim, como exemplo, o perigo de contaminação poderá ser baixo mesmo em aquíferos vulneráveis se a carga potencial de contaminação for reduzida.

FOSTER et al. (2002) consideram o perigo de contaminação da água subterrânea como a interação entre a vulnerabilidade natural do aquífero e a carga contaminante potencial associada às atividades antrópicas. Esse conceito foi aplicado em estudos no Brasil como em CARVALHO et al. (2009), CUTRIM \& CAMPOS (2010), MONTERO \& PEIXOTO (2013) e MEIRA et al. (2014).

O perigo é um dos componentes considerados na avaliação do risco que, conceitualmente, envolve também a magnitude do impacto ao alvo a proteger, no caso, a água subterrânea. De acordo com JOHANSSON \& HIRATA (2004), o perigo, conforme definido por FOSTER et al. (2002), reflete a probabilidade da água subterrânea ser contaminada, enquanto o conceito de risco envolve uma combinação entre a probabilidade e a consequência da contaminação, sendo que esta última é determinada pela ponderação do valor da água subterrânea ou da porção do aquífero afetado pela contaminação. O valor da água não é apenas do ponto de vis- ta econômico, mas também quanto ao aspecto ambiental, na manutenção do equilíbrio ecossistêmico (DE KETELAERE \& DALY 2004).

Fazendo uma analogia com os conceitos utilizados por outros autores, o perigo de contaminação adotado por FOSTER et al. (2002) corresponde ao que WANG et al. (2012) denomina de "risco básico", porque não considera a potencialidade de explotação do aquífero. Para HÖLTZ (2004) representa a "intensidade do risco", como aplicado em RAVBAR \& GOLDSCHEIDER (2007), WERZ \& HÖLTZ (2007), MIMI \& ASSI (2009) e JIMÉNEZ-MADRID et al. (2010).

Trabalhos recentes mostram que o termo "risco" de contaminação da água subterrânea tem sido utilizado frequentemente para representar apenas a interação da vulnerabilidade natural com a carga potencial contaminante, como em AL-ADAMAT et al. (2003), NGUYET \& GOLDSCHEIDER (2006), OLIVEIRA \& FRANCA-ROCHA (2010), LINHARES et al. (2014), PEREIRA JUNIOR et al. (2015), gerando, por vezes, um conflito entre os conceitos aplicados.

Nesse trabalho o mapeamento do perigo de contaminação da água subterrânea foi realizado com base no conceito estabelecido por FOSTER et al. (2002), fazendo uso das ferramentas de geoprocessamento em um ambiente de sistema de informações geográficas (SIG) para facilitar o cruzamento das informações. A área de estudo abrangeu seis municípios localizados no centro-leste do Estado de São Paulo: Capivari, Rafard, Elias Fausto, Monte Mor, Indaiatuba e Salto (Figura 1), caracterizados por intenso crescimento econômico e consequente processo de expansão urbana. 


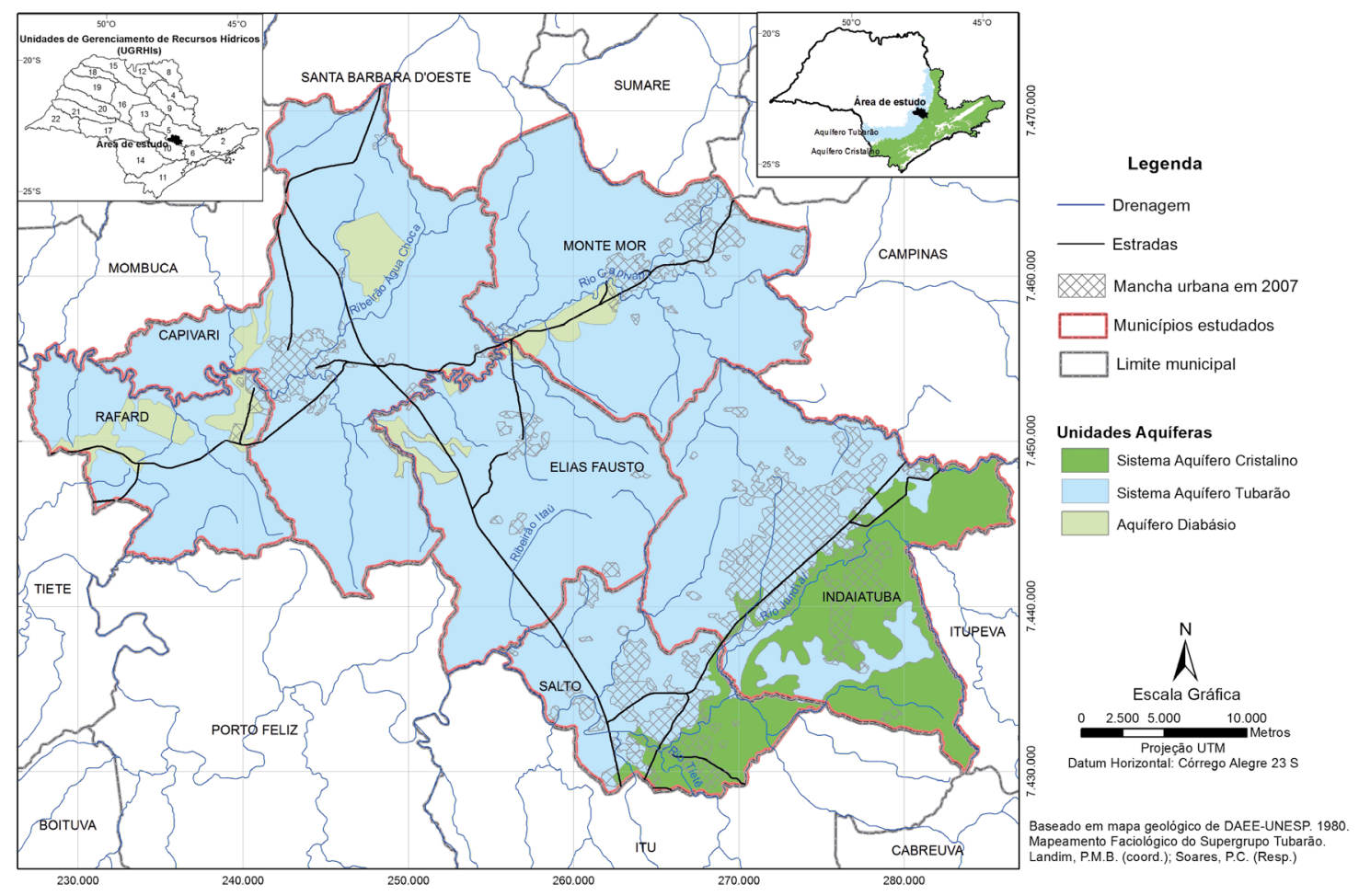

FIGURA 1 - Localização da área de estudo.

\section{METODOLOGIA}

Neste estudo, o mapeamento de perigo de contaminação da água subterrânea foi realizado considerando como fatores de análise a vulnerabilidade natural dos aquíferos e a carga contaminante potencial associada às atividades antrópicas, seguindo os conceitos estabelecidos por FOSTER et al. (2002) (Figura 2).

A vulnerabilidade natural, também denominada de vulnerabilidade intrínseca, baseia-se apenas nas propriedades físicas do aquífero e representa sua suscetibilidade a uma eventual contaminação da água subterrânea (ZAPOROZEC 1994).

A análise do perigo de contaminação baseou-se no mapa de vulnerabilidade natural dos aquíferos elaborado por DAEE \& UNESP (2010). A vulnerabilidade natural foi mapeada pelo método GOD (FOSTER \& HIRATA 1988), que considera a acessibilidade da zona saturada à penetração de poluentes e a capacidade de atenuação de poluentes, estimadas a partir: 1) da forma de ocorrência da água subterrânea (ou a condição do aquífero quanto ao confinamento hidráulico) (G); 2) dos tipos litológicos acima da zona saturada do aquífero, grau de consolidação e características granulométricas e litológicas (O); e 3 ) da estimativa da profundidade do nível d'água (D). O produto desses três fatores $(\mathrm{G} \times \mathrm{O} \times \mathrm{D})$ define, de forma relativa, as classes de vulnerabilidade natural do aquífero (FOSTER et al. 2002). Para o mapeamento, DAEE \& UNESP (2010) utilizaram mapas geológicos na escala 1:250.000 e um mapa potenciométrico elaborado com base em mapas topográficos na escala 1:50.000, gerando um mapa da vulnerabilidade natural dos aquíferos, com resolução espacial de $50 \mathrm{~m}$.

A carga contaminante potencial corresponde à atividade que armazena, utiliza, produz ou dispõe substâncias que podem contaminar o solo e as águas subterrâneas (JOHANSSON \& HIRATA 2004, FOSTER et al. 2002). As fontes potenciais de contaminação do tipo difusa foram identificadas a partir do mapeamento de uso e cobertura da terra, na escala 1:100.000, realizado com base nas imagens Landsat-TM de 2007, e do detalhamento do uso do solo urbano obtido pela interpretação de imagens SPOT 2007-2008, com resolução espacial de 2,5 m (IG 2013). As fontes potenciais de contaminação do tipo pontual foram cadastradas em 2011 por IG (2013) a partir de levantamento de empreendimentos na escala 1:10.000. A classificação da carga contaminante potencial foi realizada por IRITANI et al. (2013), que aplicaram uma adaptação do método POSH (FOSTER et al. 
2002). As fontes pontuais e difusas classificadas quanto à carga potencial contaminante foram utilizadas como base na análise do perigo de contaminação da água subterrânea no presente estudo.

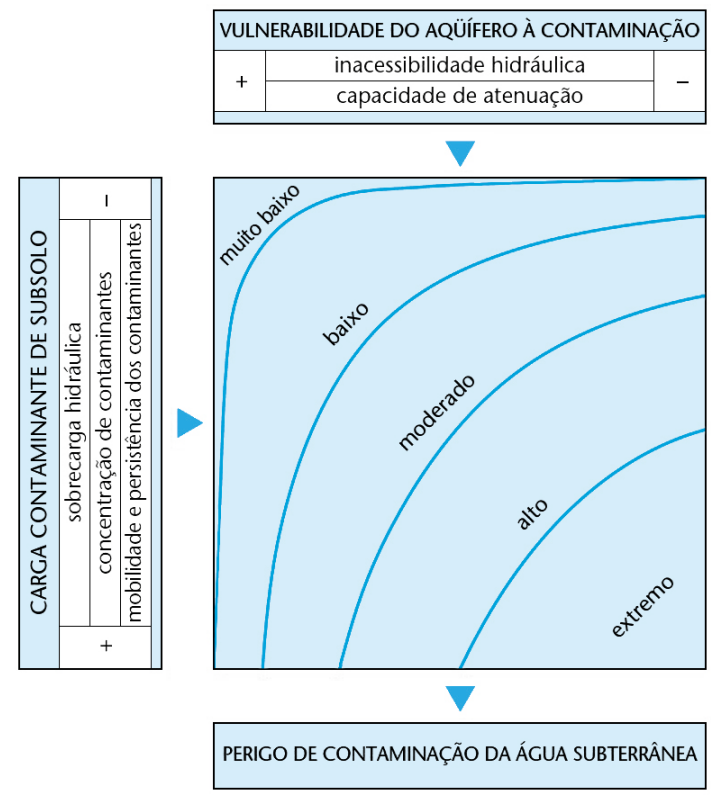

FIGURA 2 - Esquema conceitual para análise do perigo de contaminação da água subterrânea (FOSTER et al. 2002).

IRITANI et al. (2013) classificaram a carga contaminante de fontes pontuais de acordo com o tipo de atividade predominante (deposição de resíduos sólidos, tipo de indústria, lagoas de águas residuais, mineração e exploração de petróleo, entre outras), diferenciando 3 níveis: 1) reduzida, 2) mo- derada e 3) elevada. As fontes difusas também foram classificadas em três níveis de potencial contaminante considerando o sistema de saneamento in situ (situação de cobertura de rede de esgoto associada à densidade populacional) nas áreas urbanas e as práticas agrícolas (tipo de culturas, sistema de cultivo, pastagem, eficiência de irrigação, entre outros) na área rural.

No presente estudo, as fontes potenciais do tipo difusa e do tipo pontual foram consideradas separadamente, sendo desenvolvido um modelo de classificação de perigo de contaminação da água subterrânea adequado a cada uma destas fontes. $\mathrm{O}$ mapeamento do perigo foi efetuado com o apoio do SIG ArcGIS (ESRI 2008), a partir da aplicação de operações analíticas voltadas para a reclassificação, mensuração, sobreposição (overlay), integração e modelagem dos dados.

A classificação do perigo de contaminação da água subterrânea por fontes difusas foi estabelecida com base nos critérios apresentados na tabela 1 .

A classificação do perigo de contaminação por fontes difusas foi realizada a partir da operação de sobreposição (overlay) que consistiu no cruzamento dos planos de informação da vulnerabilidade natural e da carga potencial difusa gerada pelo sistema de saneamento na área urbana e pela atividade agrícola na área rural.

No mapeamento do perigo de contaminação por fontes pontuais, a área de estudo foi discretizada em uma malha regular (células de $200 \mathrm{~m}$ por $200 \mathrm{~m}$ ), a partir da criação de um plano de informação em formato raster, com resolução de $200 \mathrm{~m}$.

TABELA 1 - Classificação do perigo de contaminação da água subterrânea por fontes potenciais difusas (área urbana e rural) (adaptado de FOSTER et al. 2002).

\begin{tabular}{|c|c|c|c|c|c|}
\cline { 2 - 5 } \multicolumn{2}{c|}{} & \multicolumn{4}{c|}{ ÍNDICE DE VULNERABILIDADE NATURAL DOS AQUÍFEROS } \\
\cline { 2 - 6 } & Baixo & Médio & Alto & Extremo \\
\hline \multirow{2}{*}{} & Reduzida & Muito Baixo & Baixo & Moderado & Moderado \\
\cline { 2 - 6 } & Moderada & Baixo & Moderado & Alto & Alto \\
\cline { 2 - 6 } & Elevada & Moderado & Alto & Alto & Extremo \\
\hline
\end{tabular}


Em cada célula da grade raster procedeu-se a contagem do número de fontes potenciais de contaminação pontual, que apresentavam a maior classe de carga contaminante.

Por exemplo, se uma célula possuía 5 fontes pontuais, sendo 3 delas classificadas com moderada carga contaminante e as demais como classe reduzida, a informação associada a essa célula foi: Carga moderada; Quantidade 3. De acordo com o número de ocorrências de fontes com a maior carga contaminante, a célula foi separada em três categorias: até 4 , de 5 a 10 e acima de 10 .

Posteriormente, o plano de informação contendo a vulnerabilidade natural do aquífero também foi espacializado em uma grade raster com resolução de $200 \mathrm{~m}$ e foi cruzado com o plano de informação da carga potencial contaminante, conforme critérios apresentados na tabela 2.

TABELA 2 - Classificação do perigo de contaminação da água subterrânea por fontes potenciais pontuais (baseado em FOSTER et al. 2002).

\begin{tabular}{|c|c|c|c|c|c|c|}
\hline & & \multirow{2}{*}{$\begin{array}{c}\text { Célula de } 200 \times 200 \mathrm{~m} \\
N^{o} \text { de ocorrências por } \\
\text { célula }\left(^{*}\right)\end{array}$} & \multicolumn{4}{|c|}{ VULNERABILIDADE NATURAL DOS AQUÍFEROS } \\
\hline & & & Baixa & Média & Alta & Extrema \\
\hline \multirow{4}{*}{ 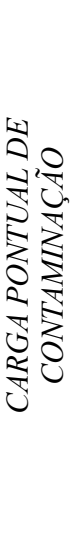 } & $\begin{array}{l}\text { Muito } \\
\text { reduzida }\end{array}$ & $\begin{array}{c}\text { Até } 4 \\
5 \text { a } 10 \\
\text { Acima de } 10\end{array}$ & $\begin{array}{l}\text { Muito baixo } \\
\text { Muito baixo } \\
\text { Muito baixo }\end{array}$ & $\begin{array}{l}\text { Muito baixo } \\
\text { Baixo } \\
\text { Baixo }\end{array}$ & $\begin{array}{l}\text { Baixo } \\
\text { Baixo } \\
\text { Baixo }\end{array}$ & $\begin{array}{l}\text { Baixo } \\
\text { Baixo } \\
\text { Baixo }\end{array}$ \\
\hline & Reduzida & $\begin{array}{c}\text { Até } 4 \\
5 \text { a } 10 \\
\text { Acima de } 10\end{array}$ & $\begin{array}{l}\text { Baixo } \\
\text { Baixo } \\
\text { Baixo }\end{array}$ & $\begin{array}{c}\text { Baixo } \\
\text { Baixo } \\
\text { Moderado }\end{array}$ & $\begin{array}{l}\text { Moderado } \\
\text { Moderado } \\
\text { Moderado }\end{array}$ & $\begin{array}{l}\text { Moderado } \\
\text { Moderado } \\
\text { Moderado }\end{array}$ \\
\hline & Moderada & $\begin{array}{c}\text { Até } 4 \\
5 \text { a } 10 \\
\text { Acima de } 10\end{array}$ & $\begin{array}{c}\text { Baixo } \\
\text { Baixo } \\
\text { Moderado }\end{array}$ & $\begin{array}{l}\text { Moderado } \\
\text { Moderado } \\
\quad \text { Alto }\end{array}$ & $\begin{array}{l}\text { Alto } \\
\text { Alto } \\
\text { Alto }\end{array}$ & $\begin{array}{l}\text { Alto } \\
\text { Alto } \\
\text { Alto }\end{array}$ \\
\hline & Elevada & $\begin{array}{c}\text { Até } 4 \\
5 \text { a } 10 \\
\text { Acima de } 10\end{array}$ & $\begin{array}{l}\text { Moderado } \\
\text { Alto } \\
\text { Alto }\end{array}$ & $\begin{array}{l}\text { Alto } \\
\text { Alto } \\
\text { Alto }\end{array}$ & $\begin{array}{c}\text { Alto } \\
\text { Extremo } \\
\text { Extremo }\end{array}$ & $\begin{array}{l}\text { Extremo } \\
\text { Extremo } \\
\text { Extremo }\end{array}$ \\
\hline
\end{tabular}

(*) Número de fontes pontuais de contaminação com a maior classe de carga contaminante na célula avaliada

\section{3 ÁREA DE ESTUDO}

No Brasil, a unidade básica territorial para o gerenciamento dos recursos hídricos é a bacia hidrográfica. O Estado de São Paulo, localizado no sudeste brasileiro, é compartimentado em 22 bacias hidrográficas denominadas de Unidades de Gerenciamento de Recursos Hídricos (UGRHI).

A área de estudo que abrange os municípios de Indaiatuba, Salto, Monte Mor, Elias Fausto, Capivari e Rafard, apresenta $1.342 \mathrm{~km}^{2}$ e está inserida na sua quase totalidade na UGRHI 5 , que compreende a Bacia dos rios Piracicaba, Capivari e Jundiaí. Apenas uma pequena área dos municípios de Salto e Rafard encontra-se na UGRHI 10, que compõe a Bacia dos rios Sorocaba e Médio Tietê (Figura 1).

Estes seis municípios apresentam uma população total em torno de 430.000 habitantes (IBGE
2010), quase totalmente concentrada na área urbana, principalmente nos municípios de Salto e Indaiatuba, onde o setor industrial destaca-se como principal atividade econômica. Nos municípios de Capivari, Rafard e Monte Mor predomina a cultura canavieira voltada para agroindústria e em Elias Fausto destaca-se a agropecuária como a mais importante atividade econômica do município.

A rede de esgotamento sanitário atende mais de $90 \%$ da população da área urbana destes municípios, com exceção de Monte Mor, que apresentou um índice de coleta de esgoto de 65 \% em 2015 (CETESB 2016).

$\mathrm{O}$ abastecimento de água pela rede pública é de quase $100 \%$ na área urbana dos municípios, sendo que a água subterrânea abastece totalmente Elias Fausto e Rafard e parcialmente Capivari (64\%) e Monte Mor (46\%) (SNIS 2008). 
A água subterrânea é também um importante recurso tanto para o usuário privado dos setores industrial e comercial, como para o usuário doméstico. Segundo estimativa de IG (2013), em 2010, aproximadamente $76 \%$ do volume explotado nos 1262 poços cadastrados nos municípios estudados no presente estudo era utilizado por usuários privados.

A maior parte dos poços (cerca de 70\%) e do volume explotado (cerca de $80 \%$ ) corresponde ao Sistema Aquífero Tubarão (IG 2013), que constitui a principal unidade hidroestratigráfica em termos de extensão na área estudada (Figura 1). É um aquífero granular, bastante heterogêneo por constituir-se de litotipos de granulação variável, interdigitados e intercalados (Figura 3). Regionalmente tem comportamento livre, mas, em locais com maior ocorrência de litotipos argilosos ao longo do pacote sedimentar, o aquífero pode apresentar condições de confinamento ou semi-confinamento.

$\mathrm{Na}$ área estudada, o Sistema Aquífero Tubarão (SAT) compreende rochas sedimentares permo-carboníferas do Subgrupo Itararé do Grupo Tubarão (Figura 3), depositadas em ambiente marinho, fluvial e glacial, representadas por associações de arenitos, siltitos, folhelhos, argilitos, diamictitos e ritmitos (PETRI \& PIRES 1992, PETRI et al. 1996). Parte da Bacia Sedimentar do Paraná, o Subgrupo Itararé aumenta a espessura no rumo oeste do estado de São Paulo, com maiores valores na área de Monte Mor e Capivari, onde alcança mais de $400 \mathrm{~m}$ (Figura 3) (ODA et al. 2012).

O SAT abrange uma faixa extensa no leste do estado de São Paulo e, regionalmente, apresenta baixa produtividade (geralmente inferior a $0,10 \mathrm{~m}^{3}$ $\mathrm{h}^{-1} \mathrm{~m}^{-1}$ ). Entretanto, os municípios de Capivari, Rafard, Elias Fausto e Monte Mor apresentam áreas com maior produtividade, com capacidade específica média superior a $0,25 \mathrm{~m}^{3} \mathrm{~h}^{-1} \mathrm{~m}^{-1}$, principalmente onde há maior ocorrência de fácies arenosas em subsuperfície (ODA et al. 2016).

As coberturas cenozóicas (Figura 3) recobrem parte do Sistema Aquífero Tubarão e são caracterizadas pela pequena espessura, por sua constituição mais arenosa e pelo menor grau de consolidação, podendo desempenhar papel importante para a recarga do SAT.

Sotoposto ao SAT encontra-se o Embasamento Cristalino (Figura 3), composto por rochas pré-cambrianas, predominantemente gnaisses e granitos (HASUI et al. 1981), que compõem o Sistema Aquífero Cristalino (Figura 1), onde o armazenamento e a circulação das águas subterrâneas ocorre nas fraturas da rocha sã e também no manto de alteração.

Rochas intrusivas básicas da Formação Serra Geral, cretáceas, com ocorrência irregular e esparsa principalmente nas porções oeste e norte da área estudada (Figura 3), formam eventualmente um aquífero local, de pouca importância, denominado de Aquífero Diabásio (Figura 1).

\section{VULNERABILIDADE NATURAL DOS AQUÍFEROS}

O mapeamento da vulnerabilidade natural da porção leste do Estado de São Paulo executado por DAEE \& UNESP (2010) baseou-se no método GOD (FOSTER \& HIRATA 1988) e considerou apenas as porções livres dos aquíferos, sendo que os tipos litológicos foram obtidos de mapas geológicos na escala 1:250.000.

As rochas que predominam na área estão agrupadas no Subgrupo Itararé, associadas a solos silto-argilosos a siltosos, enquanto a cobertura cenozóica e aluviões são consideradas sedimentos não consolidados, com solos de granulação bastante grossa.

Os materiais de alteração do Embasamento Cristalino nos municípios de Salto e Indaiatuba correspondem a solos silto-arenosos a arenosos, enquanto os corpos de diabásio da Formação Serra Geral em Rafard, Capivari, Monte Mor e Elias Fausto foram associados aos solos silto-argilosos.

DAEE \& UNESP (2010) consideraram as drenagens como áreas de descarga dos aquíferos. A partir dos pontos de intersecção das drenagens com as curvas topográficas, gerou-se uma superfície numérica que, subtraída das cotas do modelo digital do terreno (MDT), resultaram na espacialização da profundidade do nível da água subterrânea.

As classes de profundidade de nível d'água adotadas por DAEE \& UNESP (2010) foram: menor que $2 \mathrm{~m}, 2$ a $5 \mathrm{~m}, 5$ a $10 \mathrm{~m}, 10$ a $20 \mathrm{~m}$ e maior que $20 \mathrm{~m}$.

O Mapa de Vulnerabilidade Natural, com resolução espacial de $50 \mathrm{~m}$, gerado a partir da interação desses fatores mostra que na região estudada os aquíferos apresentam vulnerabilidade baixa a média. As áreas de alta a extrema vulnerabilidade ocorrem localmente, ao longo da rede de drenagem, como verificado no sul de Indaiatuba e norte de Capivari, e em algumas regiões de cabeceiras, como em Elias Fausto (Figura 4). 

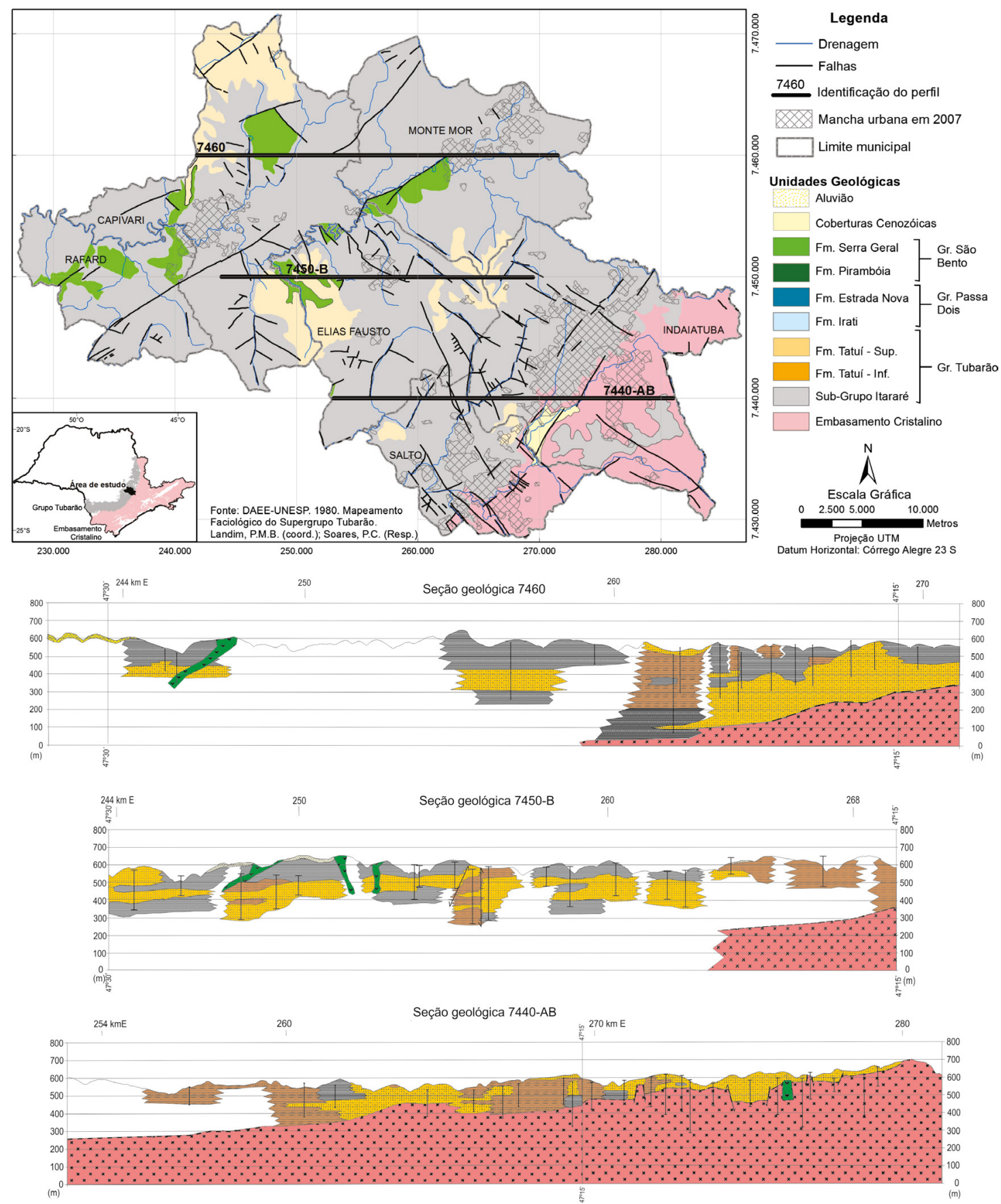

Arenitos $\quad$ Siltitos e Ritmitos Argilitos e Folhelhos $\quad$ Cenozóico $\quad$ Diabásio

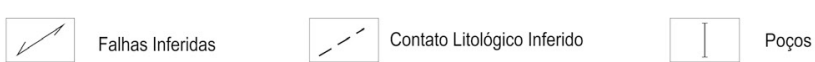

FIGURA 3 - Mapa geológico simplificado e seções geológicas da área de estudo (adaptado de Oda et al. 2012). 


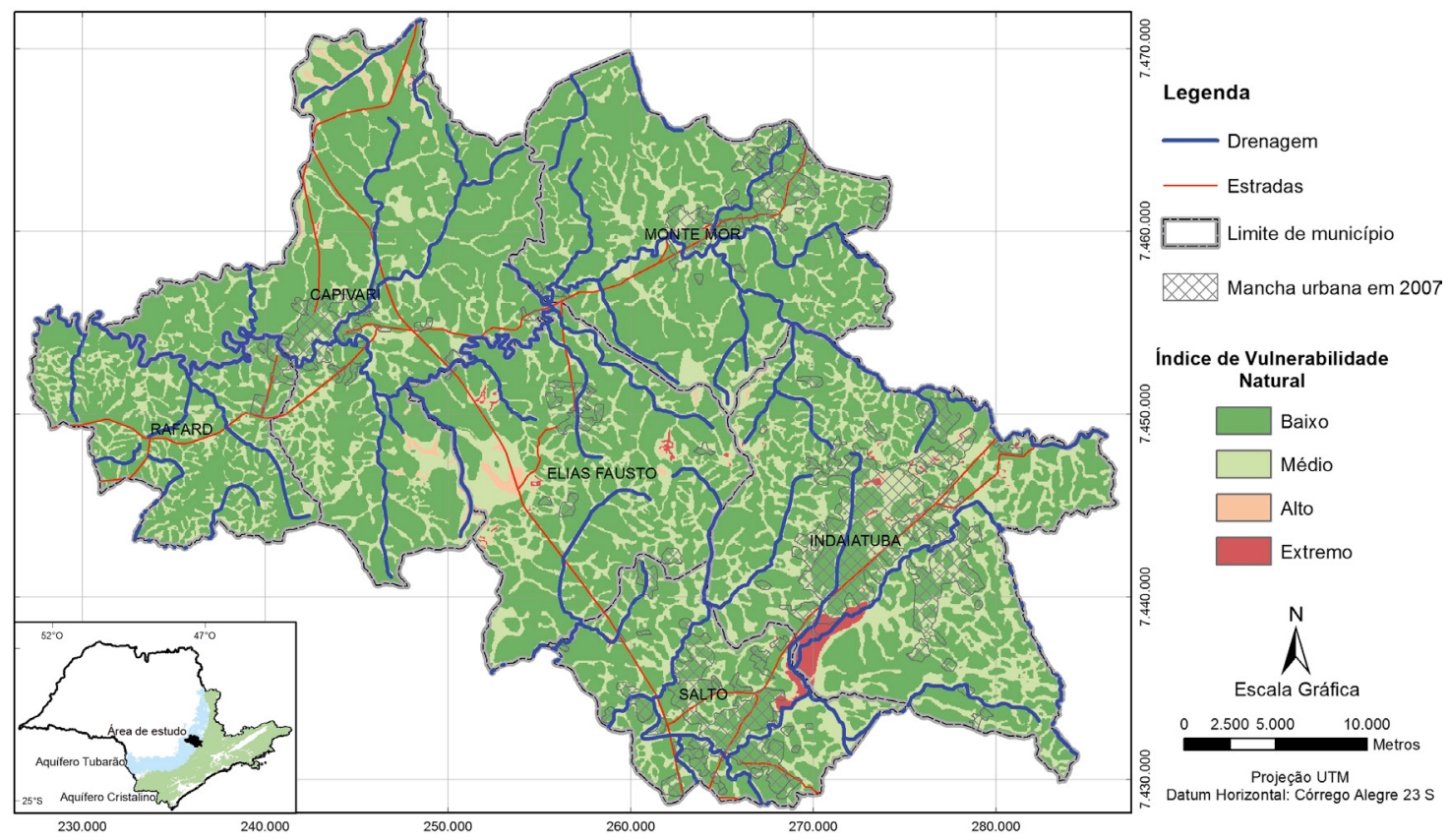

FIGURA 4 - Mapa de Vulnerabilidade Natural dos aquíferos na área estudada (DAEE \& UNESP 2010).

\section{FONTES POTENCIAIS DE CONTAMINAÇÃO}

As áreas urbanas foram consideradas fontes potenciais de contaminação difusa, especialmente devido ao nitrato, associadas à infiltração de efluentes domésticos no solo provenientes do sistema de esgotamento sanitário. De acordo com IRITANI et al. (2013) as cargas contaminantes elevadas localizam-se nas porções mais antigas das cidades, onde ocorre alta densidade de ocupação (Figura 5). A área urbana de Monte Mor destaca-se pela elevada carga potencial de contaminação resultante do baixo índice de atendimento por rede de esgoto que, em 2013, era em torno de 50\% (CETESB 2014) e, em 2014 e 2015, era de 65\% (CETESB 2015, 2016).

$\mathrm{Na}$ área rural, as cargas contaminantes mais elevadas associadas à contaminação difusa proveniente da aplicação de agroquímicos concentravam-se, principalmente, nos municípios de Capivari e Rafard, onde a cultura canavieira era dominante na época do estudo de IRITANI et al. (2013) (Figura 5).

$\mathrm{Na}$ área de estudo, um total de 1835 fontes potenciais de contaminação pontual foram identificadas em 2011 e classificadas quanto à carga contaminante, sendo $82 \%$ destas relacionadas à atividade industrial, localizadas, principalmente, nos municípios de Indaiatuba e Salto. Apenas estes dois municípios concentravam 1207 indústrias e 141 estabelecimentos comerciais, ativos e desativados (IRITANI et al. 2013).

Um conjunto de 1077 empreendimentos classificados como elevada e/ou moderada carga potencial contaminante (Figura 6) está relacionado a indústrias, principalmente do setor químico/farmacêutico (102), de engenharia mecânica (277) e de produtos metálicos (426) e eletroeletrônicos (109). O comércio varejista de combustíveis, classificado como moderada carga contaminante, destaca-se por corresponder a $49 \%$ das atividades comerciais analisadas.

\section{RESULTADOS}

\subsection{Perigo de contaminação por fontes difusas}

Os mapas de perigo de contaminação da água subterrânea por fontes difusas, relativos à área urbana e à área rural, apresentam predomínio das classes de perigo moderado a muito baixo como resultado da baixa vulnerabilidade dos aquíferos (Figuras 7 e 8). 

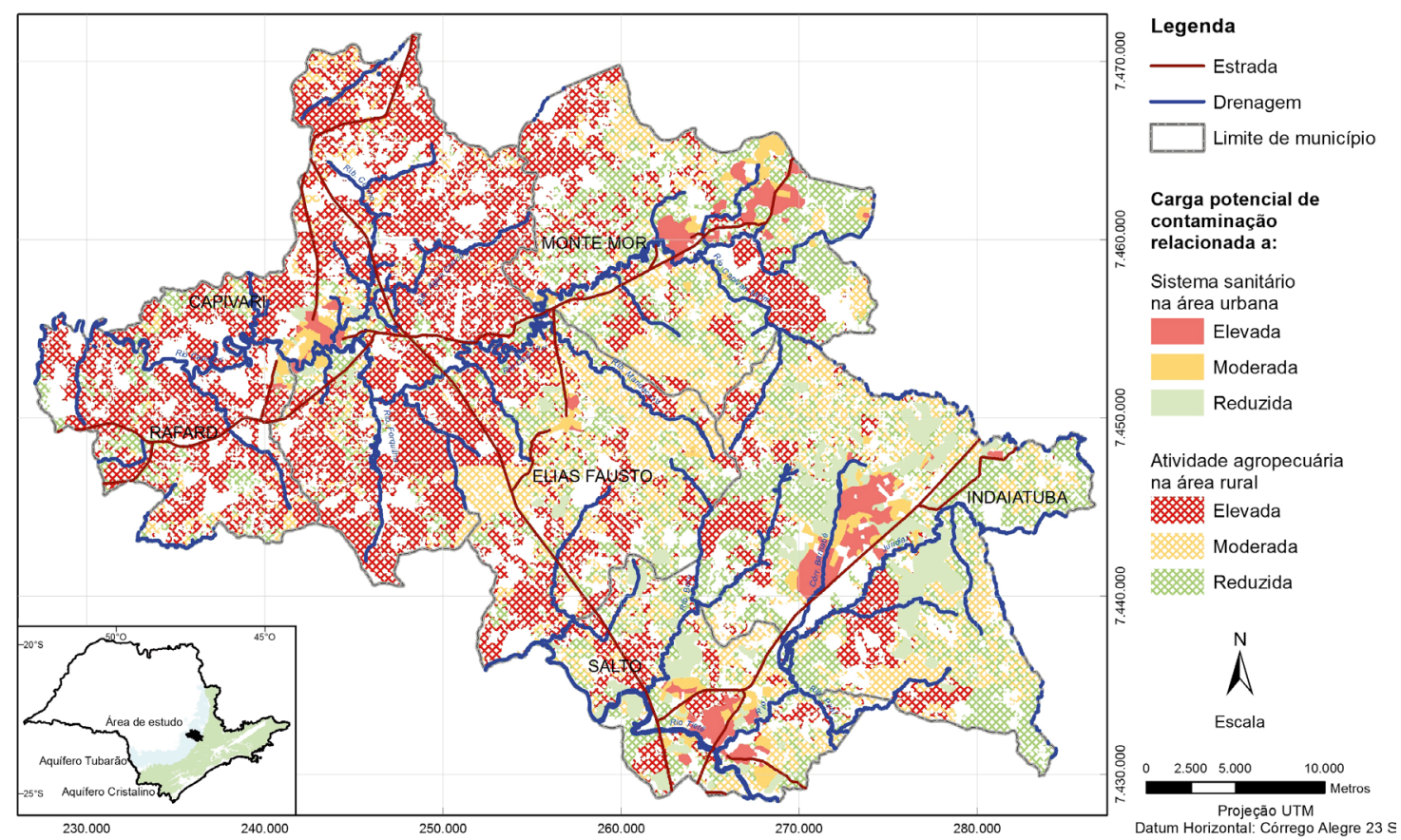

FIGURA 5 - Mapa das Fontes de Contaminação Difusa da água subterrânea proveniente dos sistemas de saneamento (área urbana) e de atividade agropecuária (área rural) (modificado de IRITANI et al. 2013).

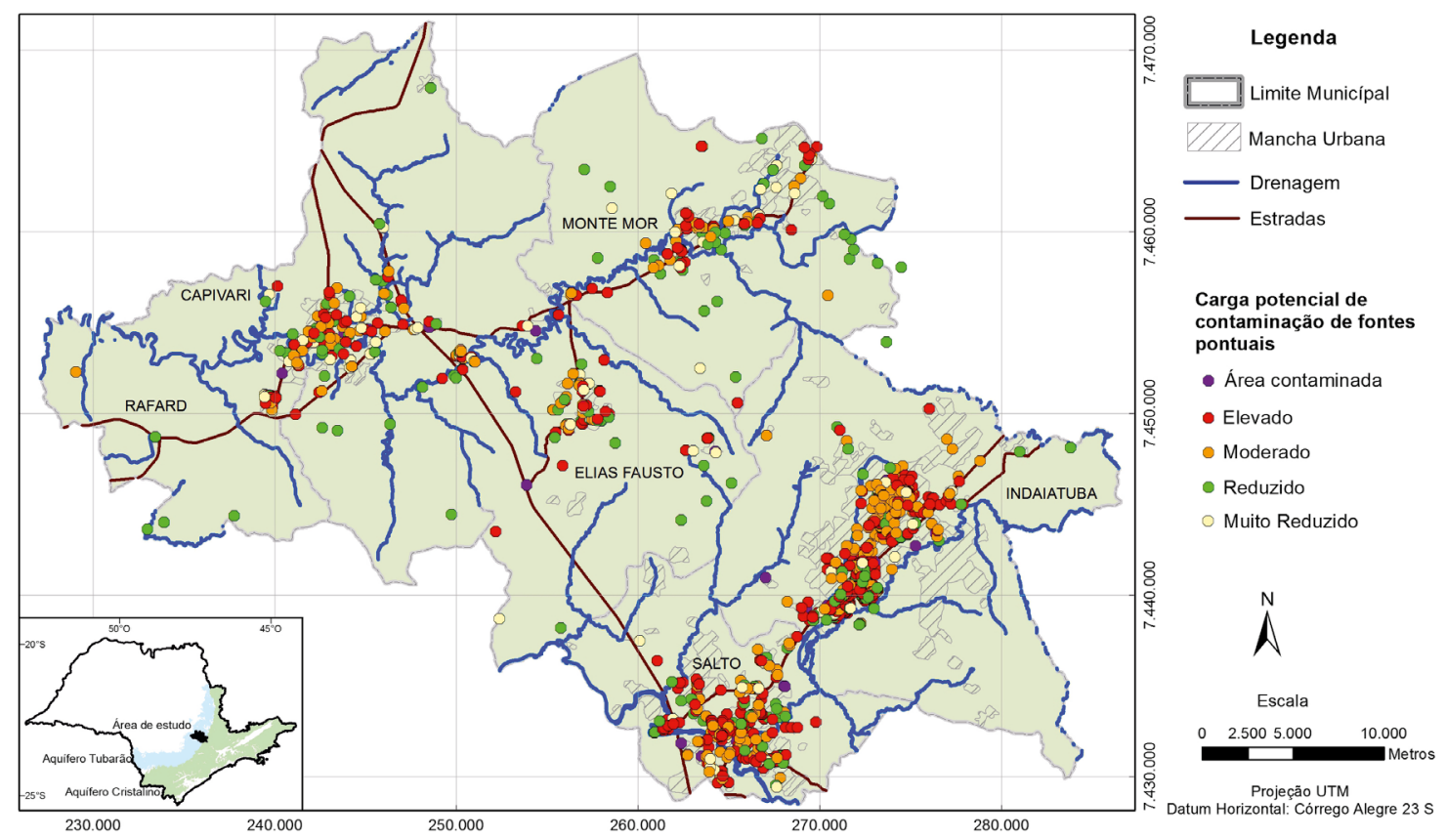

FIGURA 6 - Mapa das Fontes de Contaminação Pontuais (modificado de IRITANI et al. 2013).

O maior perigo de contaminação é proveniente da infiltração de efluente doméstico que se concentra nas porções de urbanização mais antiga e com maior adensamento (Figura 7), onde a carga potencial contaminante é mais elevada (Figura 5).
Contudo, apenas $10,1 \%$ e $0,1 \%$ da área urbana total apresentaram, respectivamente, alto e extremo perigo de contaminação A maior parte apresentou moderado $(29,8 \%)$, baixo $(29,4 \%)$ ou muito baixo (30,6\%) perigo de contaminação. 

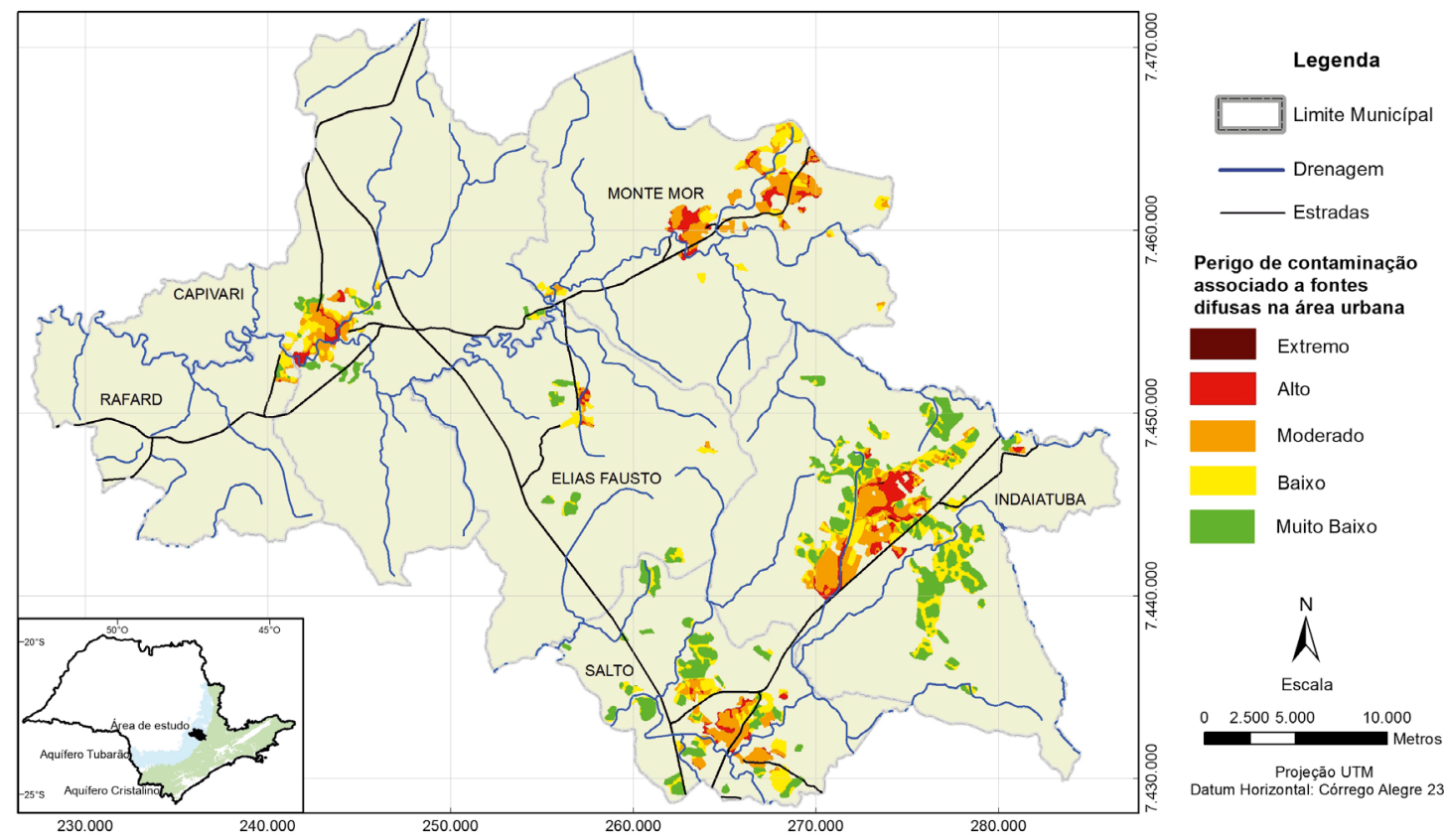

Perigo de contaminação associado a fontes difusas na área urbana Extremo

Alto

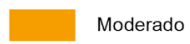

Baixo

Muito Baixo

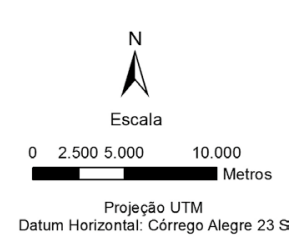

FIGURA 7 - Perigo de contaminação da água subterrânea relacionado aos sistemas de saneamento na área urbana.

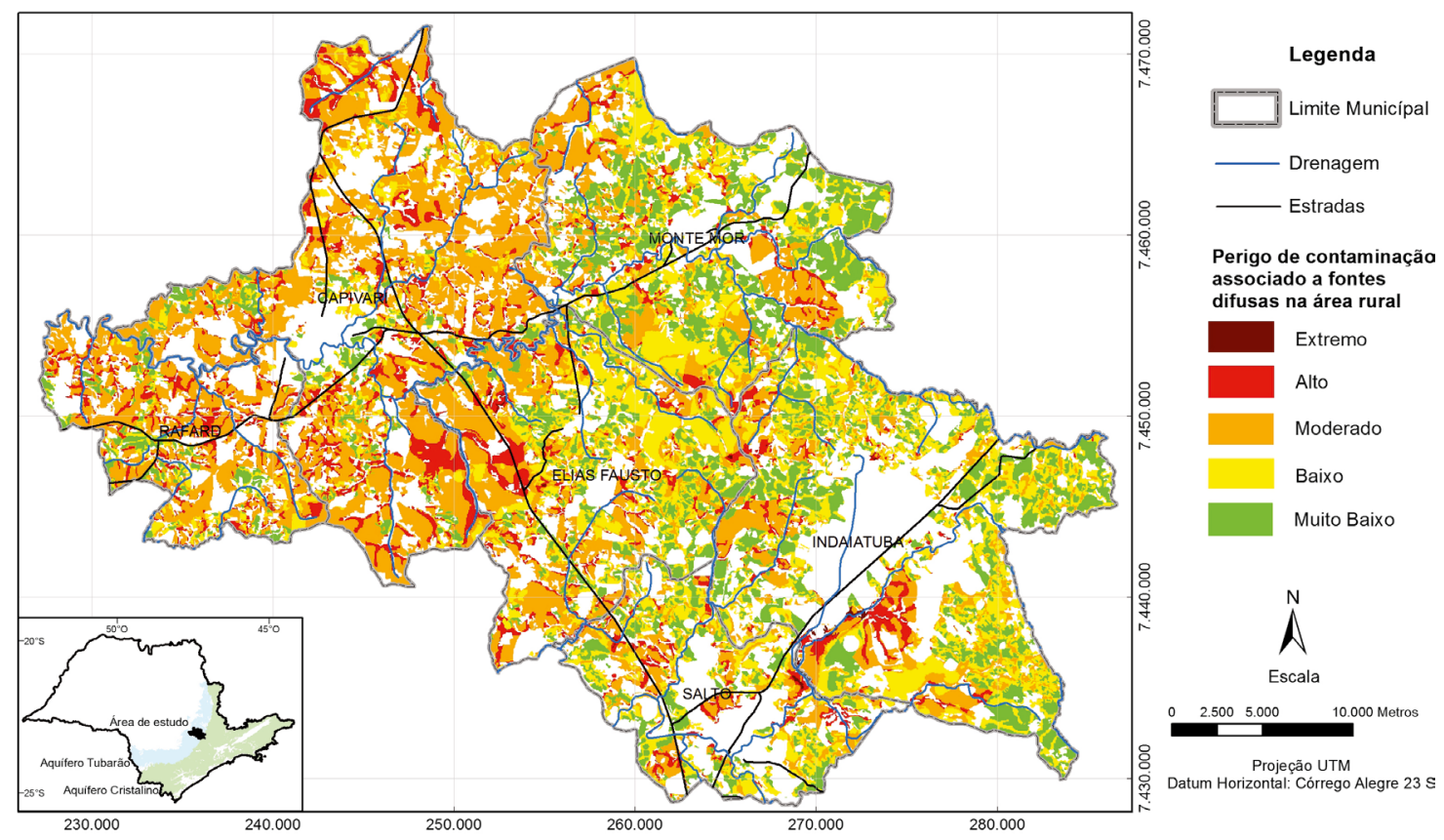

FIGURA 8 - Perigo de contaminação da água subterrânea relacionado à atividade agrícola na área rural.

Na cidade de Monte Mor, apesar da existência de elevada carga contaminante devido à pequena cobertura da rede de esgoto, grande parte da área urbana estende-se por regiões de baixa vulnerabilidade, resultando em um perigo potencial predominante- mente moderado (54\%). Esta característica pode explicar o fato de não se observar poços com altas concentrações de nitrato na cidade (EZAKI et al. 2014). Contudo, os dados de qualidade da água subterrânea na área estudada são escassos o que dificulta a va- 
lidação do mapa de vulnerabilidade dos aquíferos e de perigo potencial de contaminação da água subterrânea por fontes difusas.

O perigo potencial de contaminação, relacionado à aplicação de agroquímicos na atividade agrícola, é maior nos municípios de Capivari, Rafard e na porção oeste de Elias Fausto (Figura 8), onde há predomínio da monocultura canavieira. Porções de perigo potencial alto a moderado também estão associadas a áreas de plantação de cana em Monte Mor e Indaiatuba, e a outras culturas na várzea do rio Jundiaí onde a vulnerabilidade é muito alta. No total, as classes de perigo potencial elevado e moderado estendem-se, respectivamente, por $11,2 \%$ e $43,3 \%$ da área rural (Figura 5).

Extensa área com alto perigo potencial de contaminação é observada na divisa dos municípios de Elias Fausto e Capivari, associada a uma área de alta a média vulnerabilidade localizada na cabeceira de um afluente do rio Capivari (Figura 4).

Nos outros municípios da porção leste da área, existem extensas regiões de pasto onde o perigo potencial de contaminação da água subterrânea é menor, predominando setores de perigo baixo a muito baixo, que ocupam, respectivamente, $25,7 \%$ e $19,7 \%$ da área rural.

Pequenas áreas foram classificadas com perigo potencial extremo $(0,1 \%)$, apesar de restritas às várzeas do rio Jundiaí, em Indaiatuba.

\subsection{Perigo de contaminação por fontes pontuais}

As classes de perigo de contaminação pontual mais elevadas foram mapeadas nos distritos industriais, principalmente próximas às drenagens (Figura 9), onde a vulnerabilidade natural também é maior.

Na porção sul da área urbana de Indaiatuba, há grandes distritos industriais bem consolidados, onde se concentram indústrias geradoras de elevada carga contaminante, que formam extensas áreas de perigo potencial classificadas entre alto a extremo. Núcleos industriais já consolidados e outros em processo de consolidação foram identificados nos municípios de Salto e Capivari onde, de forma menos expressiva, também ocorrem áreas com alto perigo de contaminação.

Nos outros municípios, o perigo potencial associado às fontes de contaminação pontual é predominantemente baixo, em decorrência da baixa vulnerabilidade dos aquíferos.

Registra-se ainda que, muito embora o perigo potencial seja baixo, eventos de contaminação podem ocorrer, uma vez que o processo pode ser desencadeado tanto pelas condições operacionais precárias do empreendimento (acidentes, volume e cuidados no manuseio e armazenamento dos produtos e resíduos perigosos, entre outros), como pela mobilidade do contaminante no solo, associado ao fator tempo de sua liberação para o ambiente.

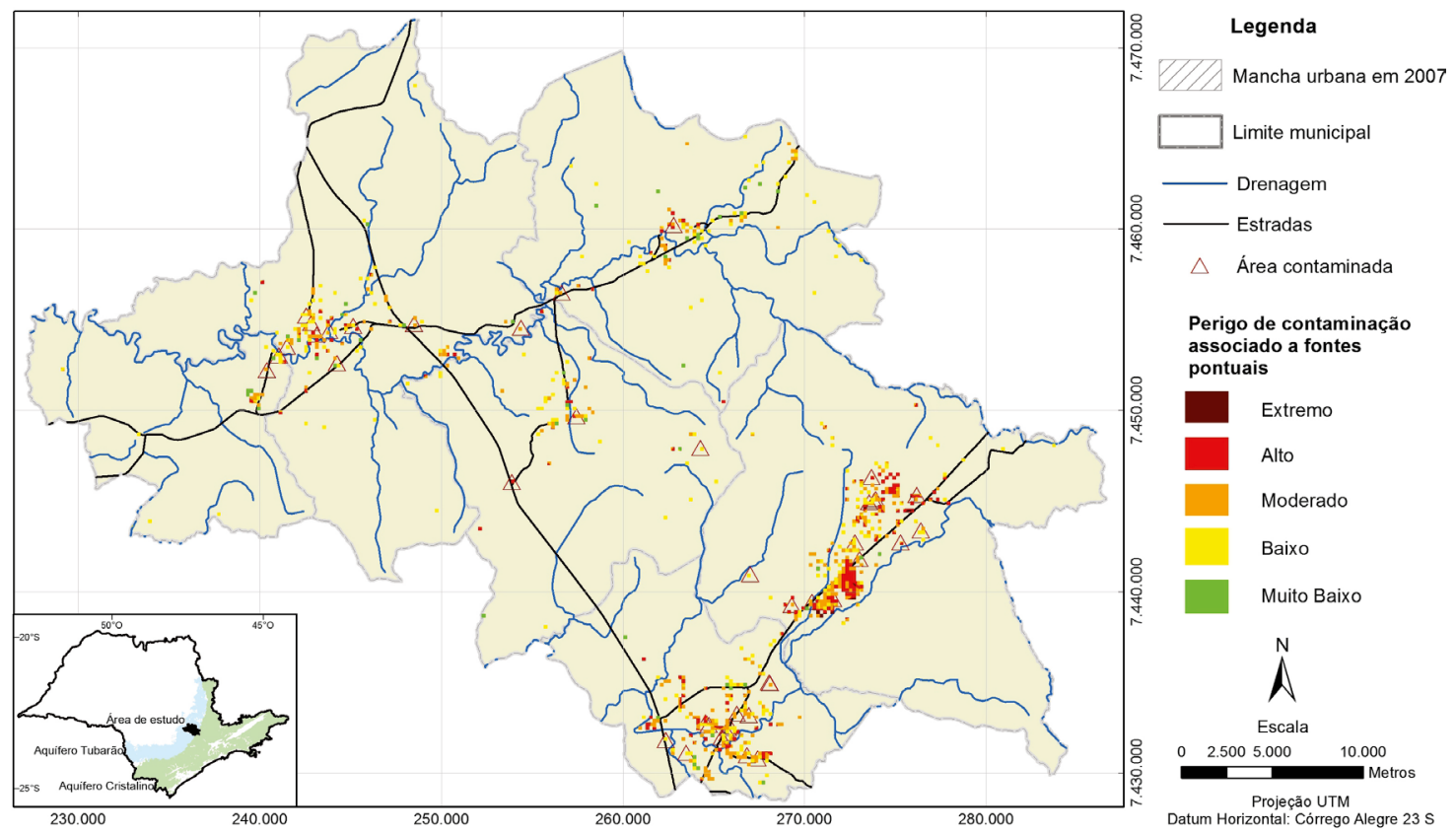

FIGURA 9 - Perigo de contaminação da água subterrânea relacionado às fontes potenciais pontuais. 
A análise do cadastro de áreas contaminadas do Estado de São Paulo (CETESB 2011) mostrou que muitas destas áreas estão localizadas em porções classificadas como de moderado a alto perigo de contaminação por fontes pontuais (Figura 9). Dentre as áreas contaminadas, predomina a contaminação proveniente do armazenamento subterrâneo inadequado de combustíveis.

\section{DISCUSSÃO}

A análise do perigo de contaminação da água subterrânea é uma forma de expressar as fragilidades dos aquíferos, auxiliando os setores administrativos, responsáveis pelo planejamento e gestão do uso do solo e dos recursos hídricos, no cumprimento de suas funções.

Muito embora este tipo de estudo possa incorporar um certo grau de incerteza por tratar-se de uma análise expedita, ele também indica áreas onde há necessidade de investigações hidrogeológicas de detalhe, podendo orientar e priorizar medidas de controle das atividades antrópicas e de proteção das captações de água subterrânea.

A implantação de programas de proteção da água subterrânea baseados na análise do perigo de contaminação deve envolver: 1) a prevenção da contaminação futura, com práticas de planejamento do uso do solo norteado pelo mapa de vulnerabilidade (onde podem ser impostas restrições a atividades contaminantes em áreas mais vulneráveis); 2) o controle das fontes potenciais de contaminação existentes, impondo práticas de operação e manutenção do empreendimento que impliquem em redução da carga potencial contaminante (por exemplo, substituição de tanques enterrados por tanques aéreos); 3) a avaliação do passivo ambiental, visando identificar contaminações existentes no solo e o risco que impõem à saúde humana e ao ecossistema, originadas por atividades atuais ou por aquelas encerradas há muitos anos (por exemplo, indústrias desativadas); 4) a seleção de áreas para perfuração de futuros poços destinados ao abastecimento público, que sejam passíveis de proteção (impondo restrições ao uso do solo e implantação de novas atividades) e onde seja possível controlar as atividades de forma a minimizar a carga potencial contaminante existente; e 5) o monitoramento sistemático: seja um monitoramento preventivo das atividades potencialmente contaminantes localizadas em áreas vulneráveis (visando detectar qualquer problema de contaminação da água subterrânea); seja um monitoramento defensivo dos poços de abastecimento público (visando alertar sobre a chegada de qualquer contaminante ao poço), seja um monitoramento intensivo de locais contaminados para garantir a eficácia das medidas de remediação (FOSTER et al. 2002).

As áreas com alto perigo de contaminação, por exemplo, indicam a presença de grande quantidade de atividades antrópicas com elevado a moderado potencial de contaminação. Nelas deve haver um esforço para minimização ou eliminação da carga potencialmente contaminante através de readequação de projeto e de operação nos empreendimentos existentes.

Nas áreas com maior vulnerabilidade é prioritária a implantação de medidas de proteção do aquífero, podendo ser aplicadas restrições ou readequações de projeto de novos empreendimentos a serem instalados, buscando minimizar o potencial de contaminação, manutenção periódica da proteção sanitária das captações de água subterrânea destinadas ao abastecimento público e, até mesmo, realocação de poços ou de fontes potenciais de contaminação.

Por outro lado, as áreas com baixa vulnerabilidade são aquelas mais adequadas à instalação de empreendimentos que apresentam maior potencial de contaminação, tais como indústrias químicas e de metalurgia, ou para a construção de poços destinados ao abastecimento de água da população, a depender da produtividade do aquífero.

Nas áreas com alta vulnerabilidade e/ou classificadas com maior perigo de contaminação por atividades pontuais, recomenda-se manter uma distância entre os poços destinados ao consumo humano e as atividades com moderada a elevada carga contaminante, conforme indicado na Deliberação CRH n ${ }^{\circ}$ 52/2005.

O mapa de perigo de contaminação auxilia na priorização das ações de planejamento e controle do uso do solo e das atividades existentes e de proteção das captações de água subterrânea. No entanto, cabe lembrar que as fontes potenciais de contaminação são transitórias e refletem o cenário do momento em que foi realizado o levantamento para o estudo. WANG et al. (2012) ressaltam que o resultado é temporário e a avaliação do perigo potencial de contaminação deve ser um processo contínuo, utilizando a informação mais atualizada para facilitar o gerenciamento da água subterrânea. 
A vulnerabilidade natural é uma característica intrínseca do aquífero, mas é determinada pela densidade de informações disponíveis no momento. Desta forma, deve ser reavaliada a medida que novos dados são obtidos para melhorar o conhecimento da área.

A habilidade do SIG para tratamento e ponderação dos dados da carga contaminante e combinação com o mapa de vulnerabilidade, fazem deste recurso de geoprocessamento um importante instrumento no processo de mapeamento do perigo de contaminação da água subterrânea, uma vez que simplificam a tarefa de produção e atualização desses mapas temáticos. Entretanto, a determinação da resolução ou do tamanho das células dos planos de informação, assim como a seleção dos critérios para ponderação da carga contaminante pontual em cada célula, influenciam na espacialização e resultado final do perigo potencial de contaminação. Neste estudo, a ponderação da carga contaminante pontual foi baseada na contagem das atividades com maior carga contaminante em cada célula. Em estudos futuros, avaliações adotando outros critérios de ponderação, associadas a uma análise de sensibilidade quanto aos parâmetros e tamanho de células adotados, podem ser realizados para comparação com os resultados apresentados nesse trabalho.

\section{CONCLUSÕES}

A avaliação do perigo de contaminação pode auxiliar na identificação de áreas prioritárias para a adoção de medidas de controle e proteção da água subterrânea.

Para a análise do perigo potencial de contaminação desenvolveu-se um método de classificação fundamentado na definição de critérios de análise e na aplicação de ferramentas de geoprocessamento. $\mathrm{O}$ mapa de perigo foi gerado a partir do cruzamento do plano de informação da vulnerabilidade natural do aquífero com o plano de informação da carga contaminante associada às atividades antrópicas.

A análise do mapa de vulnerabilidade natural indicou o predomínio de índices de vulnerabilidade baixo a médio, e escassas áreas de alta vulnerabilidade associadas à rede de drenagem. Áreas de extrema vulnerabilidade ocorrem localmente em algumas cabeceiras de drenagem nos municípios de Indaiatuba e de Elias Fausto, e também na várzea do rio Jundiaí, entre os municípios de Indaiatuba e de Salto.
A carga contaminante potencial é imposta por fontes pontuais e difusas de contaminação. $\mathrm{Na}$ área de estudo, as fontes pontuais estão associadas, em grande parte, às indústrias e ao comércio de combustíveis que se concentram, principalmente, nos municípios de Indaiatuba e de Salto.

A análise do perigo potencial de contaminação associado às fontes pontuais indicou áreas com classe alto perigo nos distritos industriais de Indaiatuba (Nova Era, Recreio Campestre Joia, Vitoria Martini, American Park Empresarial, Domingos Giomi e João Narezzi) e de Salto (Allert, Julio Ustrito e Parque do Lago). Nos outros municípios as áreas com alto perigo potencial de contaminação ocorrem de forma dispersa ao longo do rio Capivari e das rodovias.

As fontes difusas estão associadas ao sistema de saneamento das áreas urbanas e à atividade agrícola, na área rural.

O maior grau de perigo potencial de contaminação da água subterrânea associado ao sistema de saneamento das áreas urbanas encontra-se nas porções mais antigas das cidades, onde também ocorre maior adensamento urbano. Contudo, uma vez que os aquíferos geralmente apresentam baixa vulnerabilidade natural, predomina a classe moderada perigo de contaminação, até mesmo em Monte Mor, onde a carga potencial contaminante é elevada, consequência da baixa taxa de cobertura da rede de esgoto.

Por outro lado, o maior grau de perigo potencial de contaminação da água subterrânea resultante da atividade agrícola na área rural ocorre principalmente nos municípios de Capivari e Rafard e na porção oeste do município de Elias Fausto, onde há predomínio da monocultura canavieira.

A aplicação de técnicas de análise espacial em SIG facilita o cruzamento de informações georreferenciadas. Entretanto, deve ser destacado que a determinação da resolução ou do tamanho das células dos planos de informação, assim como a seleção dos critérios para ponderação da carga contaminante em cada célula influenciam na espacialização e resultado final do perigo potencial de contaminação. Esse fato ressalta a importância da escolha de parâmetros adequados à escala de trabalho e dos dados disponíveis.

Finalmente, um componente que precisa ser considerado na gestão dos recursos hídricos é a importância da água subterrânea, avaliando seu valor econômico, social e ambiental no contexto local ou regional. Apesar deste artigo não abordar estes aspectos, estudos futuros devem conside- 
rar seu valor, desenvolvendo métodos que sejam adequados ao cenário e ao nível de informação disponível em países em desenvolvimento como o Brasil, onde programas de monitoramento da qualidade da água subterrânea são escassos e descontínuos.

\section{AGRADECIMENTOS}

Este artigo foi produzido a partir dos resultados do projeto "Identificação de áreas potenciais de restrição e controle de captação e uso das águas subterrâneas na porção sul da UGRHI 05 - Projeto ArcTub1", o qual contou com financiamento do Fundo Estadual de Recursos Hídricos (Contrato FEHIDRO $n^{\circ} 450 / 2006$ ).

Os autores agradecem à colaboração do LEBAC/UNESP pelo fornecimento dos arquivos digitais do mapa de vulnerabilidade dos aquíferos e à CETESB pelo fornecimento de dados sobre as fontes potenciais de contaminação e também dos estagiários Renan Penasso Pacheco e Johann Constantino Lima na confecção de algumas figuras e na organização de parte dos dados. Aos relatores da Revista do IG pelas sugestões apresentadas.

\section{REFERÊNCIAS BIBLIOGRÁFICAS}

AL-ADAMAT, R.A.N.; FOSTER, I.D.L.; BABAN, S.M.J. 2003. Groundwater vulnerability and risk mapping for the Basaltic aquifer of the Azraq basin of Jordan using GIS, remote sensing and DRASTIC. Applied Geography, 23: 303-324.

CARVALHO, A. M.; CONICELLI, B. P.; HIRATA, R.; L'APICCIRELLA, E.S.; SIMONATO, M.D.; CAMPOS, J.E.; ROCHA, G.; SURITA, C.; PILLON, A.M.; ABREU, M.C.; BERTOLO, R.; WENDLAND, E. 2009. Estão os aquíferos da região de Jurubatuba (São Paulo) sob risco? In: ABAS, CONGRESSO INTERNACIONAL DE MEIO AMBIENTE SUBTERRÂNEO, 1, São Paulo, Anais, 10 p.

CETESB - COMPANHIA AMBIENTAL DO ESTADO DE SÃO PAULO. 2011. Relação de áreas contaminadas e reabilitadas, Dezembro 2011. CETESB, São Paulo. Disponível em http://areascontaminadas.cetesb.sp.gov. br/relacao-de-areas-contaminadas/. Acessado em 10 mai. 2012.
CETESB - COMPANHIA AMBIENTAL DO ESTADO DE SÃO PAULO. 2014. Qualidade das águas superficiais no Estado de São Paulo 2013. (C.E. Komatsu, coord.). Série Relatórios, CETESB, São Paulo, 301 p.

CETESB - COMPANHIA AMBIENTAL DO ESTADO DE SÃO PAULO. 2015. Qualidade das águas superficiais no Estado de São Paulo. 2014. (C. E. Komatsu, coord.). Série Relatórios, CETESB, São Paulo, 369 p.

CETESB - COMPANHIA AMBIENTAL DO ESTADO DE SÃO PAULO. 2016. Qualidade das águas superficiais no Estado de São Paulo. Parte 1 - Águas Doces. 2015. (C. E. Komatsu, coord.). Série Relatórios, CETESB, São Paulo, 401 p.

CRH - CONSELHO ESTADUAL DE RECURSOS HÍDRICOS. 2005. Deliberação CRH $\mathrm{n}^{\mathrm{o}} 52$, de 15 de abril de 2005. Institui no âmbito do Sistema Integrado de Gerenciamento de Recursos Hídricos - SIGRH diretrizes e procedimentos para a definição de áreas de restrição e controle da captação e uso das águas subterrâneas. CRH, São Paulo. Disponível em http://www.sigrh.sp.gov.br. Acessado em 17 fev. 2014.

CUTRIM. A.O.; CAMPOS, J.E.G. 2010. Avaliação da vulnerabilidade e perigo à contaminação do Aquífero Furnas na cidade de Rondonópolis (MT) com aplicação dos métodos GOD e POSH. Geociências, 29(3): 401-411.

DAEE - DEPARTAMENTO DE ÁGUAS E ENERGIA ELÉTRICA; UNESP - UNIVERSIDADE ESTADUAL DE SÃO PAULO. 1980. Mapeamento faciológico do Subgrupo Tubarão. Convênio DAEE-UNESP, Escala 1:50.000. DAEE/UNESP, São Paulo.

DAEE - DEPARTAMENTO DE ÁGUAS E ENERGIA ELÉTRICA; UNESP - UNIVERSIDADE ESTADUAL DE SÃO PAULO. 2010. Regionalização de diretrizes de utilização e proteção das águas subterrâneas - Bacias do Leste (Relatório Técnico).

DE KETELAERE, D.; DALY, D. 2004. Vulnerability in a risk framework. In: F. Zwahlen (ed.) COST Action 620: vulnerability and risk mapping for the protection of carbonate (karst) aquifers. Final Report. Brussels, Belgium, Office of 
the Official Publications of the European Communities, p. 84-85.

ESRI - ENVIRONMENTAL SYSTEMS RESEARCH INSTITUTE. 2008. ArcGIS for Desktop 9.3, Redlands, CA. Disponível em http://www.esri.com/software/arcgis/arcgisfor-desktop.

EZAKI, S.; ODA, G.H.; IRITANI, M.A.; VEIGA, C.; STRADIOTO, M.R. 2014. Hidroquímica dos aquíferos Tubarão e Cristalino na região de Indaiatuba-Rafard, Estado de São Paulo. Pesquisas em Geociências, 41(1): 65-79.

FOSTER, S.; HIRATA, R. 1988. Groundwater pollution risk assessment: a methodology using available data. WHOPAHO/ HPECEPIS Technical Manual, Lima, Peru, $81 \mathrm{p}$.

FOSTER, S.; HIRATA, R.; GOMES, D.; D'ELIA, M.; PARIS, M. 2002. Groundwater quality protection. A guide for water utilities, municipal authorities, and environment agencies. GW-Mate, World Bank, Washington, 103 p.

HASUI, Y.; DANTAS, A.S.L.; CARNEIRO, C.D.R.; BISTRICHI, C.A. 1981. O embasamento Pré-Cambriano e Eopaleozóico em São Paulo. In: F.F.M. Almeida, Y. Hasui, W.L. Ponçano, A.S.L. Dantas, C.D.R. Carneiro, M.S. Melo, C.A. Bistrichi (eds.) Mapa Geológico do Estado de São Paulo, escala 1: 500.000. IPT, p. 12-45, São Paulo.

HÖTZL, H. 2004. Assessment concept. In: F. Zwahlen (ed.) COST Action 620: vulnerability and risk mapping for the protection of carbonate (karst) aquifers. Final Report, Office of the Official Publications of the European Communities, Brussels, Belgium, p. 108-113.

IRITANI, M.A.; ROSSINI-PENTEADO, D.; EZAKI, S.; ODA, G.H. 2013. Proposta de classificação das fontes potenciais de contaminação da água subterrânea. Revista do Instituto Geológico, 34(2): 1-26.

IBGE - INSTITUTO BRASILEIRO DE GEOGRAFIA E ESTATÍSTICA. 2010. Cidades@ São Paulo. Disponível em http:// www.ibge.com.br/cidadesat.

IG - INSTITUTO GEOLÓGICO. 2013. Identificação de Áreas Potenciais de Restrição e
Controle de captação e uso das águas subterrâneas na porção sul da UGRHI 05. Instituto Geológico, São Paulo, 2 vols. (Relatório Técnico do Instituto Geológico).

JIMÉNEZ-MADRID, A.; MARTÍNEZ- NAVARRETE, C.; CARRASCO-CANTOS, F. 2010. Groundwater risk intensity assessment. Aplication to carbonate aquifers of the western Mediterranean (Southern Spain). Geodinamica Acta, 23(1-3): 101-111.

JOHANSSON, P.; HIRATA, R. 2004. Rating of groundwater contamination sources. In: A. Zaporozec (ed.) Groundwater contamination inventory. A methodological guide. IHP-VI, Series on Groundwater, n. 2. Paris, UNESCO, p. 63-74.

LINHARES, F.M.; ALMEIDA, C.N.; SILANS, A.M.B.P.; COELHO, V.H.R. 2014. Avaliação da vulnerabilidade e risco à contaminação das águas subterrâneas da bacia hidrográfica do rio Gramame (PB). Sociedade \& Natureza, 26(1): 139-157.

MEIRA, J.C.R.; CAMPOS, A.B.; PEREIRA, L.C. 2014. Vulnerabilidade natural e perigo à contaminação de zona de recarga do Aquífero Guarani. Águas Subterrâneas, 28(1): 31-46.

MIMI, Z.A.; ASSI, A. 2009. Intrinsic vulnerability, hazard and risk mapping for karst aquifers: a case study. Journal of Hydrology, 364: 298310.

MONTERO, R.C.; PEIXOTO, A.S.P. 2013. Vulnerabilidade e perigo de contaminação dos aquíferos no Alto Aguapeí e Alto Peixe, SP. Ciência \& Engenharia, 22(1): 115-124.

NGUYET, V.T.M.; GOLDSCHEIDER, N. 2006. A simplified methodology for mapping groundwater vulnerability and contamination risk, and its first application in a tropical karst área, Vietnam. Hydrogeology Journal, 14: 1666-1675.

ODA, G.H.; TAKEUCHI, D.M.; EZAKI, S.; IRITANI, M.A.; VARNIER, C.; PENTEADO, D.R.; LIMA, C.V.F.; SILVA, A.H.; ZUCA, N.L.; PACHECO, R.P. 2012. Geometria do Aquífero Tubarão entre os municípios de Indaiatuba e Capivari (SP). Revista do Instituto Geológico, 33(10): 23-40. 
ODA, G.H.; EZAKI, S.; IRITANI, M.A.; VARNIER, C.L.; PENTEADO, D.R. 2016. Avaliação hidrogeológica dos Sistemas Aquíferos Tubarão e Cristalino da porção sul da UGRHI-05. In: ABAS, CONGRESSO BRASILEIRO DE ÁGUAS SUBTERRÂNEAS, 19, Campinas, Anais, 16 p.

OLIVEIRA, A.I.L.; FRANCA-ROCHA, W. 2010. Proposição metodológica para modelagem da vulnerabilidade e risco dos recursos hídricos subterrâneos na sub-bacia do Alto Paraguaçu, Estado da Bahia. In: ABAS, CONGRESSO BRASILEIRO DE ÁGUAS SUBTERRÂNEAS, 16, São Luís, Anais, 15 p.

PEREIRA JÚNIOR, L.C.; SOARES, H.L.T.; CASTRO, S.S. 2015. Vulnerabilidade natural e risco de contaminação do Aquífero Bauru no município de Rio Verde - GO. Águas Subterrâneas, 29(2): 129-145.

PETRI, S.; PIRES, F.A. 1992. O Subgrupo Itararé (Permocarbonífero) na região do Médio Tietê, Estado de São Paulo. Revista Brasileira de Geociências, 22(3): 301-310.

PETRI, S.; VIEIRA, P.C.; ODA, G.H.; FERNANDES, P.B. 1996. O Subgrupo Itararé, Permocarbonífero da Região do Médio Tietê, Estado de São Paulo, estudos de subsuperfície. Revista do Instituto Geológico, 17(1/2): 63-78.

RAVBAR, N.; GOLDSCHEIDER, N. 2007. Proposed methodology of vulnerability and contamination risk mapping for the protection of karst aquifers in Slovenia. Acta Carsologica, 36(3): 397-411.

SNIS - SISTEMA NACIONAL DE INFORMACOÕES SOBRE SANEAMENTO / MINISTÉRIO DAS CIDADES. 2008. Diagnóstico dos Serviços de Água e Esgoto. Disponível em http://www.snis.gov.br.

WANG, J.; HE, J.; CHEN, H. 2012. Assessment of groundwater contamination risk using hazard quantification, a modified DRASTIC model and groundwater value, Beijing Plain, China. Science of the Total Environment, 432: 216-226.

WERZ, H.; HÖLTZ, H. 2007. Groundwater risk intensity mapping in semi-arid regions using optical remote sensing data as an additional tool. Hydrogeology Journal, 15: 1031-1049.

ZAPOROZEC, A. 1994. Concept of groundwater vulnerability. In: J. Vrba \& A. Zaporozec (ed.) Guidebook on mapping groundwater vulnerability. IAH, Hannover, International Contributions to Hydrogeology, 16: 3-7.

\section{Endereço dos autores:}

Mara Akie Iritani, Denise Rossini-Penteado, Sibele Ezaki, Geraldo Hideo Oda - Instituto Geológico, Rua Joaquim Távora 822, CEP 04015-011, São Paulo, SP, Brasil. E-mails: mara.iritani@sp.gov.br, dpenteado@sp.gov.br, sibezaki@sp.gov.br, ghoda1947@gmail.com

Artigo submetido em 3 de fevereiro de 2017, aceito em 13 de abril de 2017. 